\begin{tabular}{|l|l|l||}
\hline \multicolumn{2}{|c|}{ PublisherInfo } \\
\hline \hline PublisherName & $:$ & Palgrave Macmillan UK \\
\hline \hline PublisherLocation & $:$ & London \\
\hline \hline PublisherImprintName & $:$ & Palgrave Macmillan \\
\hline \hline
\end{tabular}

\title{
Methods explained: Index numbers
}

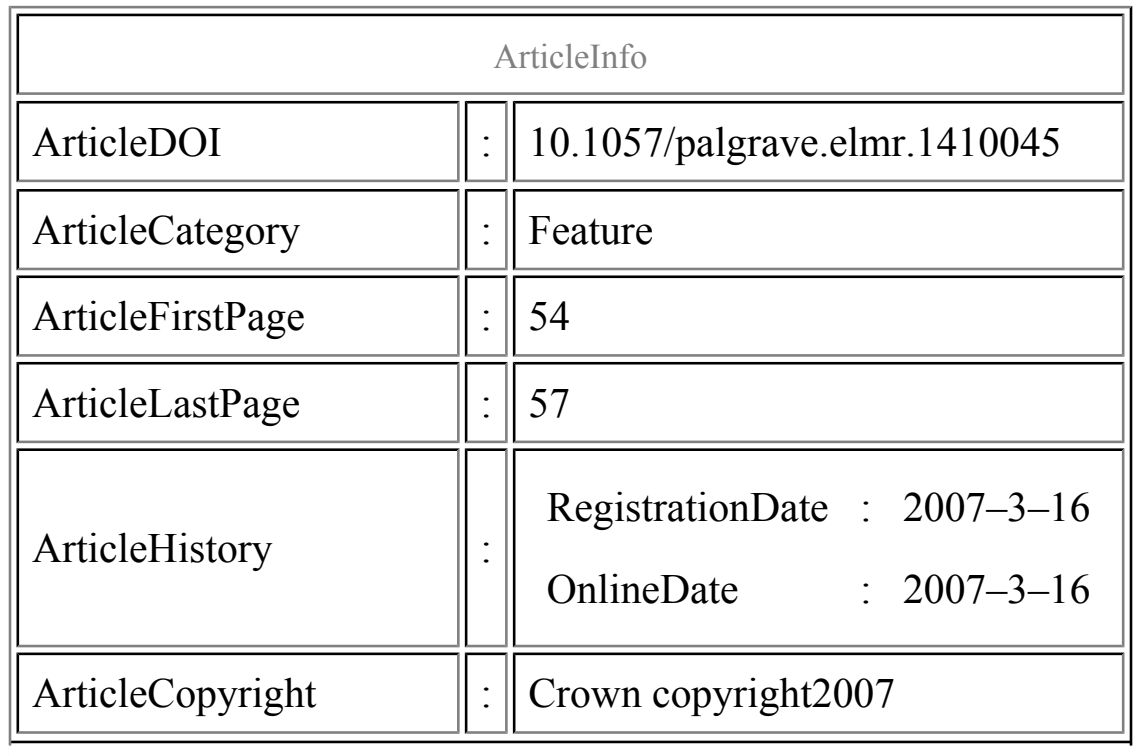


Peter Goodridge, ${ }^{\text {Affl }}$

Aff1 Office for National statistics

\section{Attempts to explain the subtle differences in the methodologies used to construct index numbers.}

Many of the statistics produced by the Office for National Statistics,particularly economic statistics, are published in the form ofindices. However, there are a number of different forms of indices and this article attempts to explain the subtle differences in themethodologies used to construct them, and also factors that feed into the choice of which type of index to use. Hypothetical examplesare provided to illustrate the effects of using different index forms.

\section{Misc}

The Full Text of this article can be found on the National Statistics website (http://www.statistics.gov.uk/elmr/03_07/downloads/ELMR03_07Methods.pdf). 